\title{
Influence of Coal Quality on Boiler Elements Abrasion
}

\author{
Lidija Joleska Bureska
}

AD ESM, TPP Bitola, Bitola, Macedonia.

How to cite this paper: Lidija Joleska Bureska. (2021) Influence of Coal Quality on Boiler Elements Abrasion. Journal of Electrical Power \& Energy Systems, 5(1), 1-7.

DOI: $10.26855 /$ jepes.2021.03.001

Received: January 25, 2021

Accepted: February 22, 2021

Published: March 3, 2021

*Corresponding author: Lidija Joleska Bureska, AD ESM, TPP Bitola, Bitola, Macedonia.

Email: lidija.j.bureska@elem.com.mk

\begin{abstract}
Depletion of the coal reserve in the main mine, which is the main fuel source for providing continuous operation of the Thermal Power Plant (TPP) Bitola, imposes the necessity of providing certain coal quantities from the new mines near to the old one. Since the new and old coal deposits have different coal quality, the processes of mixing of and inter-changing between coals from the mines, influence the system for coal preparation, in particular mills and their wheels, ducts for air-mixture, convective heat surfaces, etc. Regular reports the coal technical analysis continuously provide an insight of these changes in the coal quality and its influence of the boiler elements in Unit 1. In this paper calculated is the Abrasion Index of coals following an empirical expression developed by Raask, where influential variables are the relative weight contents of quartz, pyrites and ash found in the coal sample. In accordance with the results, classification of the coals is performed, as well as diagrams that indicate the impact of coal ash content on the coal abrasiveness and its repercussion concerning the mills, associated system components and convective heat surfaces. Further, pointed out are several recommendations regarding improving the protection of the systems from coal abrasion.
\end{abstract}

\section{Keywords}

Ash, Abrasion, Coal, Thermal power plant

\section{Introduction}

The boilers in the Power Plants are designed to work with before chosen coal which is the most favorable to provide. The coal providing can be from the local mine close to the Power Plant or to be brought from the other places or countries. As time goes on, coal reserves are reduced and Power Plant impose with problem to provide coal with the same characteristics with designed. The proximate analysis of the coals, very often can be in the range with designed coal, but ultimate analysis are different. Because of that very often a mixture of two or more different coals is made. Mixing the different coals have to be very precise in order to achieve such a ratio of individual coals in order to minimize the impact on the boiler operation. In the boilers in Power Plant Bitola last years were combusted coals from the old mine Suvodol, new mine Brod Gneotino and "floor series" from the old mine. Because ultimate analysis of the coals is different, the coal quality supplied in the boiler depends of portions of them. Reducing the one of them simultaneously increases the amount of other. Very often, increased the portion 
with high ash content causes changes of the boiler operation. Especially is making changes on the coal dust preparation system, where ash increases abrasion and wear of the mill wheels, housings, air-mix ducts, etc. Because of the high ash content in coal, abrasion occurs on heat surfaces, especially on those installed in the convective passage of the boiler.

\section{Abrasion and wear}

\subsection{Abrasion Index Classification}

Apart from its physical characteristics, coal abrasion depends on its hardness and strength, the structure of the mineral material, the dimensions, and shape of the particles (round, square, with a sharp edge, etc.). The presence of various ingredients (pyrite, sand, clay, etc.) increase or decrease abrasion, and intensify the abrasion process on the mill's elements and other coal dust preparation equipment [1].

The abrasive of the coal is a function of mineral matter characteristics. An empirical expression was developed by Raak which allows for comparative analysis of coals and is presented by the equation [2]:

$$
\mathrm{AI}=\mathrm{qc}+0.5 \mathrm{pc}+0.2 \mathrm{Ac}
$$

Where:

qc: relative weight contents of quartz,

pc: relative weight contents of pyrite,

Ac: relative weight contents of ash, found in the coal simples.

When reviewing the analysis of coals as standard industry commercial practice, it is rare to find reports defining quartz. On the other hand, pyrite is frequently identified and the reports always indicate the quantity of ash. To compensate for the lack of data, estimates for quartz and pyrites in the coal can be calculated with reasonable accuracy, employing the reports with chemical analysis for $\mathrm{SiO} 2, \mathrm{~A} 12 \mathrm{O} 3$ and sulfur $\mathrm{S}$.

The quantity of quartz in coal can be determined by expression:

$$
\mathrm{Q}_{\mathrm{c}}=0.01 \mathrm{~A}_{\mathrm{c}}\left(\mathrm{SiO}_{2}-1.5 \mathrm{Al}_{2} \mathrm{O}_{3}\right)
$$

Pyrite in coal is estimated by:

$$
\mathrm{pc}=1.3(\mathrm{~S}-0.3)
$$

These equations can be used as reasonable substitutes for laboratory data in the abrasion index equation. Raak categorized the results of the abrasion index equation into for levels of abrasion as is shown in Table 1.

Table 1. Abrasion Index Classification [1]

\begin{tabular}{cc}
\hline Abrasion Index (AI) & Category \\
\hline$<4$ & Slightly (Low) abrasive \\
$\mathbf{4 - 8}$ & Moderately abrasive \\
$\mathbf{8 - 1 2}$ & Highly abrasive \\
$>\mathbf{1 2}$ & Exceptionally abrasive \\
\hline
\end{tabular}

\subsection{Abrasiveness of coal burned in the boilers of Power plant Bitola}

The Abrasion Index of the coals combusted to TPP Bitola in the period from 2005 to 2018 [3], was calculated according Raask expression. The input data were taken from the laboratory reports on the annual coal simples for the relevant year. According to the classifications in Table 1, for the period from 2005 to 2010 coal is classified as Moderate abrasive, and after 2010 to 2018 as highly abrasive. Namely, for 2005 - AI is 5.16; for 2011- AI is 9.35 and for 2016-AI is the highest i.e. 11.43. The changes in AI in the above mentioned period are shown in Figure 1.

If we compare the technical characteristics of coal burned from 2005 to 2018 [3] with designed coal [4] (Table 2), it can be seen that in the years until 2012, the proximate analyze correspond or are in the range with designed coal (Table 2). While in the years after 2012, there was a significant increase in ash content and a decrease in LHV. This increase in ash content cause increases the value of the coal Abrasion Index (Figure 1). 
The change in coal characteristics is the result of more intensive exploitation of the new mines (Brod Gneotino) and "floor series", as the old Suvodol mine was depleted.

The data in [3] and the AI calculation show that coal burned in boilers after 2012 is more abrasive than before. Changes in abrasiveness indicate that the ultimate analysis of coal from new mines is different from the project one, and is reflected, among other things, in increasing the abrasion of elements and equipment for preparing coal dust and heat surfaces in the boiler, especially on the heat surfaces installed in convective ducts. The main reason for more intense abrasion is increases the ash and quartz content. The same can be concluded from the diagrams in Figure 1 and Figure 2, where are very striking changes in the ash and quartz content.

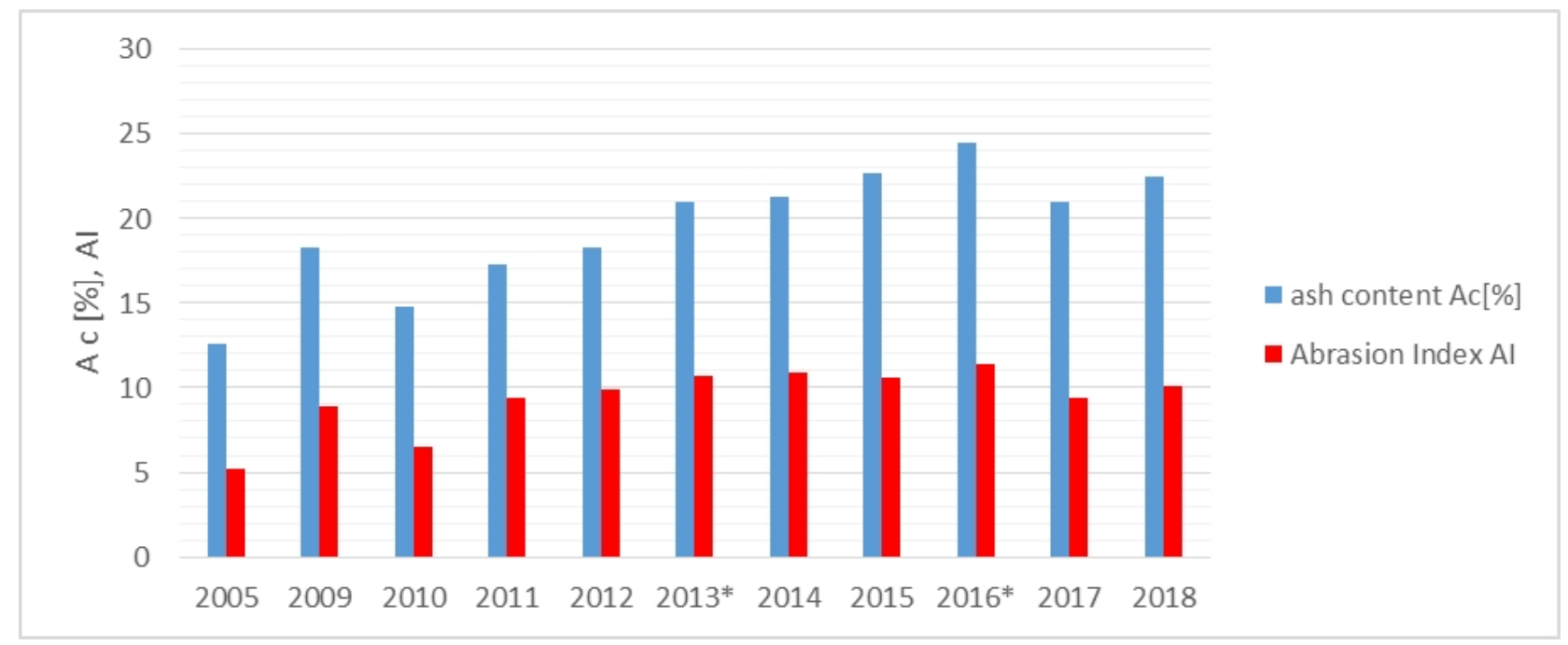

Figure 1. Changes in ash content and coal Abrasion Index in period from 2005 to 2018.

Table 2. Technical characteristic of design coal [8]

\begin{tabular}{ccccc}
\hline & Tag & Design Coal & Best Coal & Worst Coal \\
\hline Water & $\mathrm{W}[\%]$ & 52.25 & 49.5 & 49 \\
Ash & $\mathrm{A}[\%]$ & 13.5 & 12.4 & 20 \\
Low Heat Value & $\mathrm{LHV}[\mathrm{kJ} / \mathrm{kg}]$ & 7,308 & 8,070 & 6,478 \\
\hline
\end{tabular}

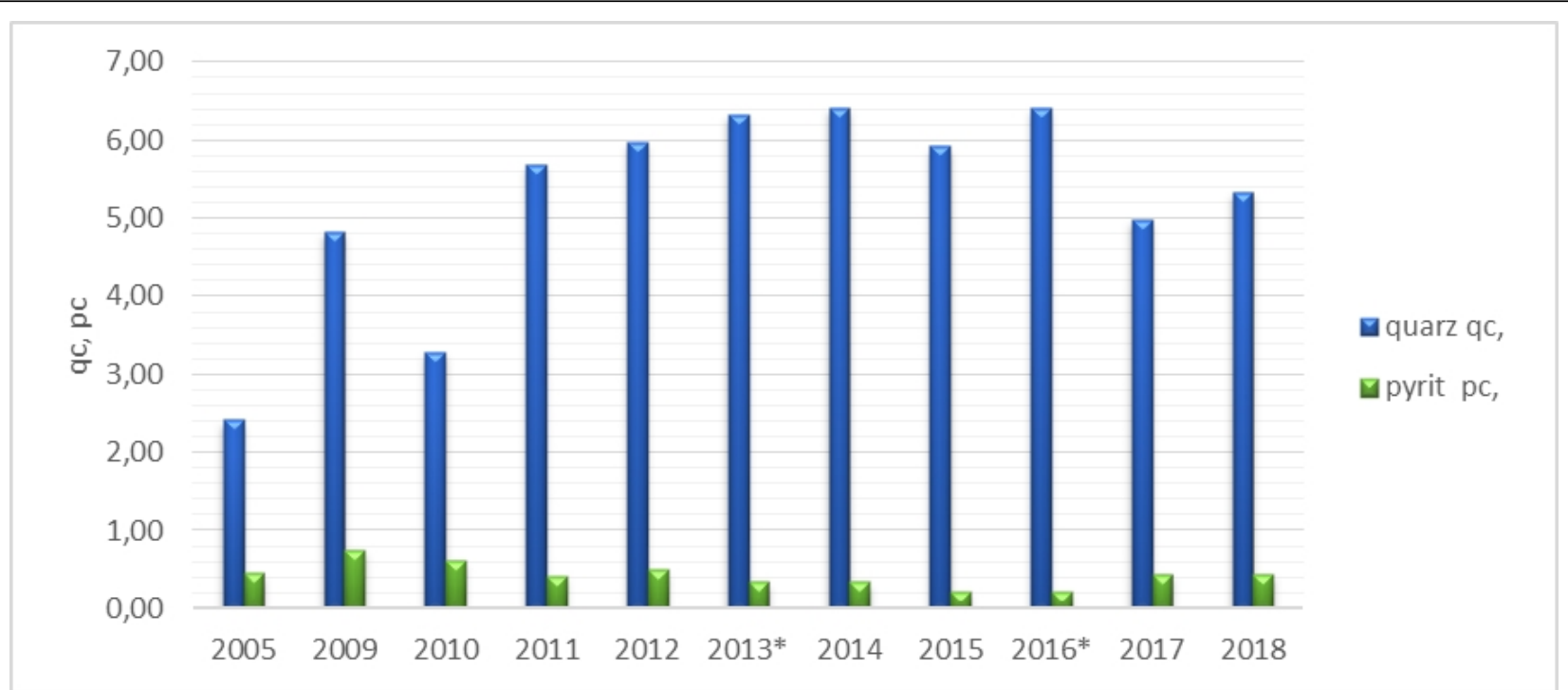

Figure 2. Changes the quartz and pyrite content in coal. 
The abrasion index increases linearly with the increase of ash content in coal, due to the quartz in them. Figure 3 shows how the ash content impacts the abrasiveness of coal [1].

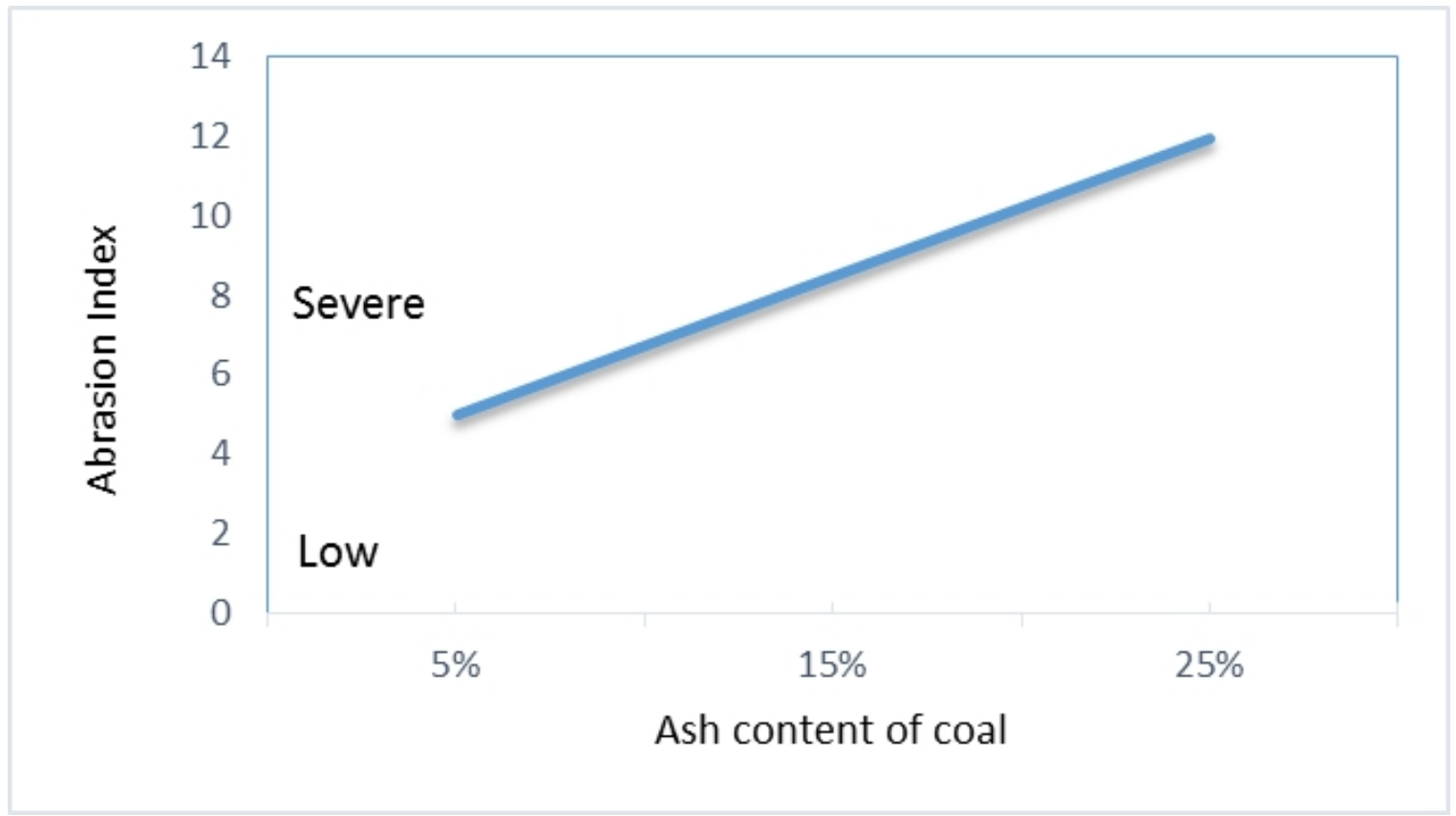

Figure 3. Increase in coal Abrasion Index with increasing ash content [1].

\section{Influence of coal abrasion on the system for coal dust preparation}

From the above expressions and diagrams, we can conclude that the increased ash content causes an increase in the coal abrasion index. But the question is what are the consequences per boiler operation and how does it affect the boiler elements?

When coal comes in the boiler with a higher ash content (low LHV), in order to maintain the same heat output of the boiler, the amount of coal in the system for coal dust preparation increases (feeders and conveyors for coal, mills and air mixing ducts). In that case, the system will be more loaded. That increase in coal in the whole system will cause greater wear of the material due to: the high ash content in the coal, increased coal flow and increased gas flow in the convective ducts.

The parts which are particularly exposed to greater wear and tear and where maintenance to be increased are:

$\square$ Mill's beater wheels and houses, including diffuser elements;

Classifiers for coal dust;

$\square$ Distributors and ducts for coal dust, especially bends on the ducts;

$\square$ Coal burners.

By analyzing the operation of the mills during 1,000 working hours, with unchanged boiler output, I obtained the following results:

When the boiler works with worse coal quality (with $20 \%$ ash), mills are $100 \%$ loaded and $18 \mathrm{t} / \mathrm{h}$ more coal passes through each mill, than when it works with better coal quality (with $12 \%$ ash) and mills are $70 \%$ loaded. Or almost $100 \mathrm{t} / \mathrm{h}$ more coal passes through all the mills. In this case, the flow of coal through the mills increases by $42 \%$ (see Figure 4).

Namely, when the boiler works with worse coal quality (with $20 \%$ ash), the abrasion is increased for two reasons. One is the increased flow of coal to maintain the same heat output of the boiler and the other reason is the increased percentage of ash in the coal which has a direct impact on increasing the Abrasion Index.

The increases abrasion is the most visible in the mill's beater wheels, especially when mills are forced (overload) to work with worse coal quality, in order to increase boiler heat output.

Namely, when the ash content in coal increases significantly, the working hours of the mill beater wheels are reduced from 1,800 to 600 hours [5] (Figure 5). In this case, the usual wheel inspection is at 250 operating hours, 
while in other case was at 500 hours. The situation is the same with stator parts of the mills (spiral). In recent years, due to increased abrasion on the stator plates in the mills, the spiral is replaced even tree times per year. The above mentioned more frequent inspections and replacement of wear parts of mills increase the power plant's costs. There are costs for the purchase and replacement of wear and tear parts and cost due to the consumption of the oil as a compensation for coal, during ongoing inspection and repairing of the mill.

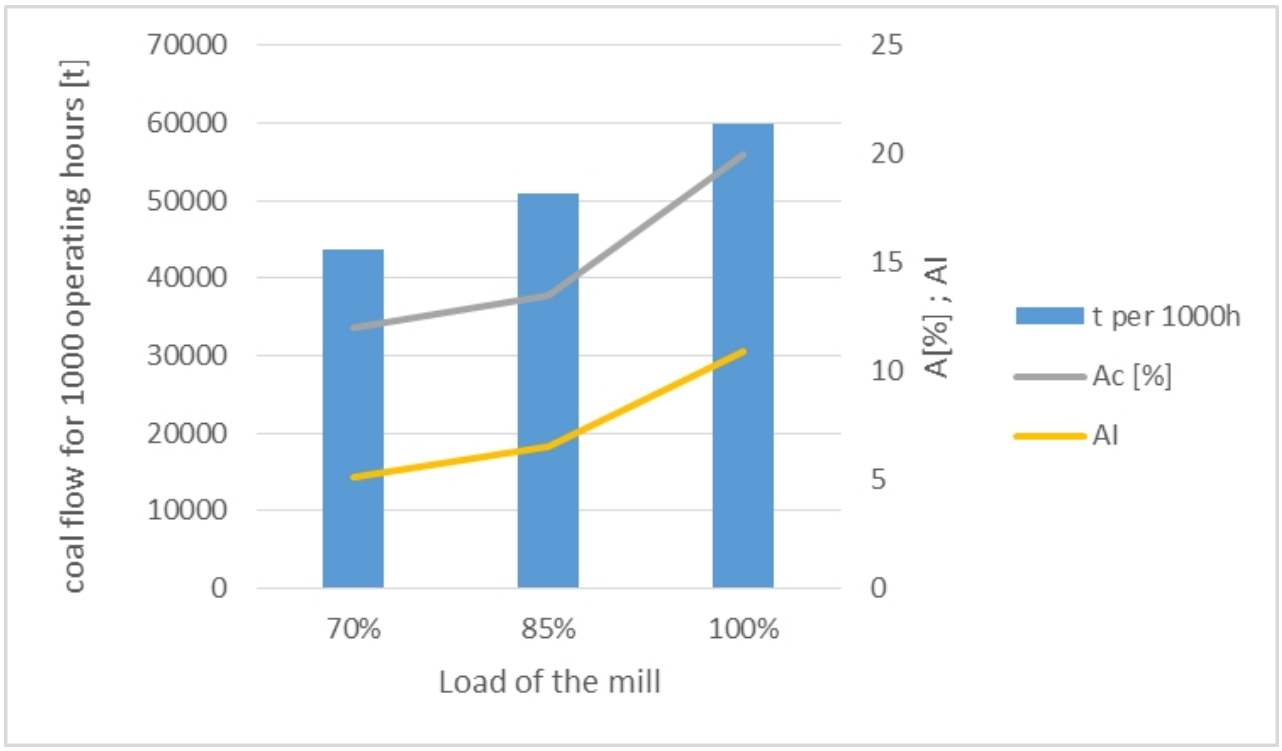

Figure 4. Change of mill load and coal flow through one mill during 1,000 working hours depending on the ash content at maximum boiler load.

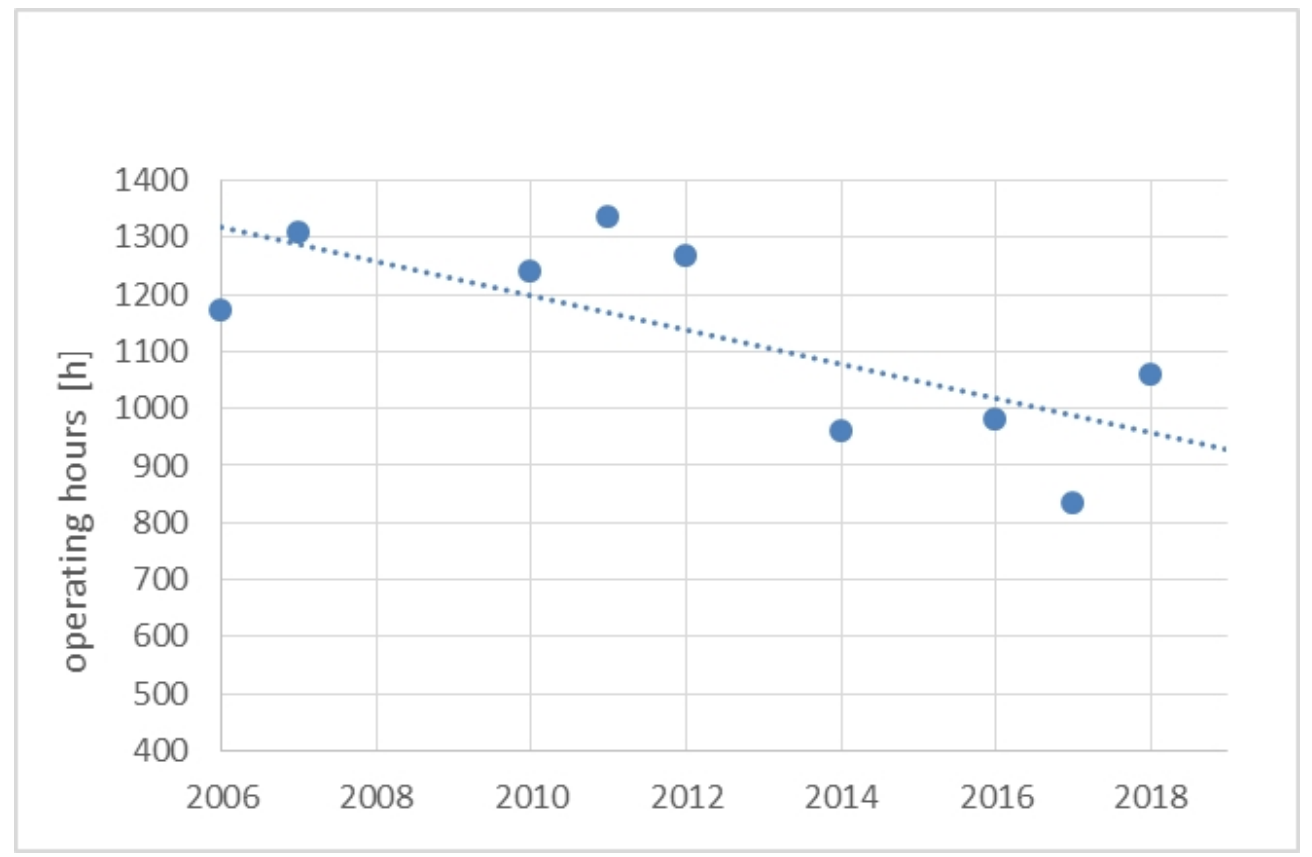

Figure 5. Average operating hours of the mill beater wheels on Unit 1 [5].

\section{Influence of the coal abrasion on the pressure parts in the boiler}

The abrasion of the pressure parts in the boiler, particularly pressure parts located in the convective ducts is related to the amount of quartz in the fly ash and the velocity of the flue gas. The survival of the quartz in the combustion process is directly related to coal dust fineness, flame temperature, unburned carbon and retention time 
in the furnace. Finer grinding and classification on the pulverized coal reduces quartz survival. While staged firing and sub-stoichiometric conditions in the burner zone, for NOx control will increase the survival factor for quartz [2].

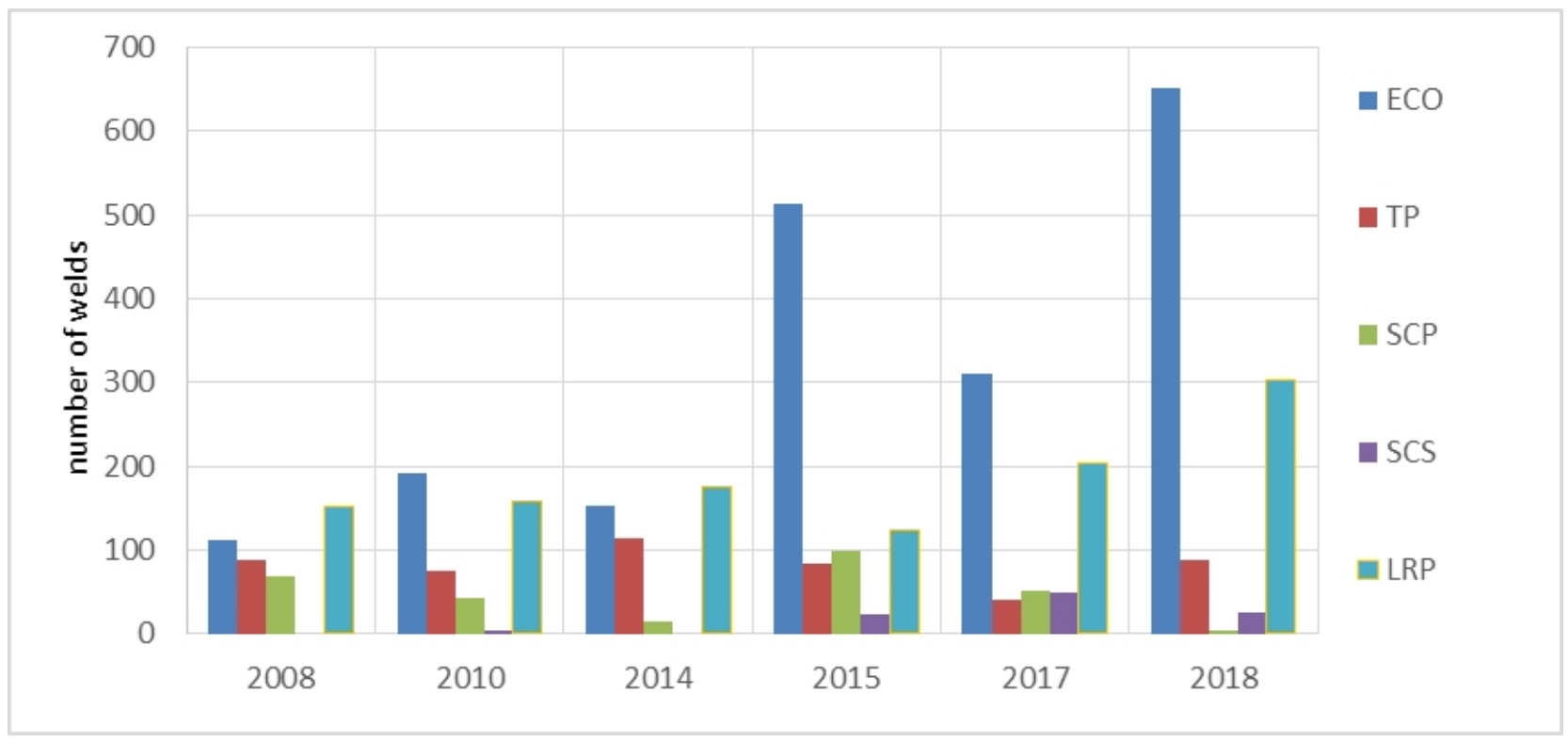

Figure 6. Number of welds did during the overhaul on Unit 1 [6].

Notes: ECO - economizer, TP-transition part, SCP-convective superheater primary steam, SCS - convective superheter secondary steam, LRP_-low radiation part (evaporation part).

Similar to the above analysis, the increases in the load of the boiler by burning coal with high ash content will cause increased abrasion on the pressure parts in the convective ducts due to the increased gas flow and high ash content in the coal. It is known, that the intensity of abrasion is directly proportional to the concentration of solid particles and their velocity in the third degree [7,8]. Since data for flue gas velocity are lacking, if it is assumed that the flue gas velocity does not change and the ash content of the coal varies depending on the coal quality, while boiler load is constant, then an increase in ash concentration will cause increased heat surfaces abrasion. Abrasion on heat surfaces is visible on the primary and secondary superheaters and economizers, located into the convective ducts of the boiler. Confirmation of this situation is the multiple increases of replaced bends and tubes due to the abrasion during boiler overhauls in the last 3 or 4 years (Figure 6).

\section{Conclusions and recommendations}

From the analyses of the coal burned in the boiler in analyzed period, its content of ash content, quartz and pyrite, and thus their impact on the boiler from the point of view of abrasion, the following can be concluded:

- The increased ash content in the coal causes an increase in its Abrasion Index, according Raasks' equations, and coals from the mine Brod Gneotino and "floor series" are classified as high abrasion coals.

- In order to achieve maximum heat output of the boiler by combusting coal with $20 \%$ ash content, it is necessary to increase the flow of coal by $43 \%$.

- Abrasion increases for two reasons: one is due to the high ash content in the coal, and the other is due to the increased flow of the coal to maintain the required boiler heat output.

- Increased coal flow increases the abrasion on the boiler elements.

- Due to the high Abrasion Index of the coal in the boiler in TPP Bitola, the operation hours of the mill's beater wheels have been reduced by more than twice.

- The abrasion is visible and increased on the pressure parts installed into the convective ducts of the boiler. Increased coal abrasion increases the Power Plant's costs for procurement and replacement of wear and tear materials from the coal dust preparation system for, pressure parts and their maintenance.

Recommended measures to protect and reduce abrasion are:

- $\quad$ reducing a load of the mills in the case when coming coal with $20 \%$ and more ash; 
- $\quad$ good maintenance and made timely inspection and repairs of the system for coal dust preparing especially mills;

- $\quad$ use of hard materials resistant to abrasion of coal for mills and other elements on the system for coal dust preparing or surfacing them with hard electrodes on the side exposed to abrasion;

- $\quad$ for pressure parts, increased inspection during the overhauls and putting the protective sheets on the parts exposed to abrasion or their metallization without disturbing heat transfer.

\section{References}

[1] T. Zivanovic, L. J. Brkic, and D. Tucakovic. (2005). Calculation of the plants for preparing coal dust, Mechanical Faculty, University in Beograd, Beograd.

[2] E. Raask. (1985). Mineral Impurities in Coal Combustion, Hemisphere Publishing Corp.

[3] Mining Institute d.o. Beograd: Test report, physical and chemical characteristics for coal TPP Bitola—annual analysis for 2005 and from 2009 to 2017.

[4] S. Pecakov. (n.d.). Local instruction for exploitation steam boiler. Pp. 700-13, 8-545 (P. 65).

[5] Annual reports for Boiler maintenance, TPP Bitola, 2006 to 2018.

[6] Reports of Boiler overhauls, TPP Bitola 2008 to 2018.

[7] Tickner, W. R. (2005). Maier, Design Considerations for Pulverized Coal Fired Boilers Combusting Ilinois Basin Coals, Electric Power 2005, Chicago, Illinois, USA.

[8] I. J. Petrovski. (2004). Steam boilers, Skopje 2004.

[9] E. Raask. (1988). Erosion Wear in Coal Utilization, Hemisphere Publishing Corp.

[10] Lj. Brkic, M. Hrnjacek, M. Calic. (1973). Steam boiler special chapters, Mechanical Faculty, University in Beograd, Beograd.

[11] L. J. Bureska. (2016). Influence of the coal quality on the boiler efficiency and opportunity for improvement, GREDIT 2016, Skopje 31.03-01.04.2016, University Cyril and Methodius, Technical Campus.

[12] L. J. Bureska. (2018). Influence of the mills maintenance on their capacity and capacity of the boiler, GREDIT 2018, Skopje 29.03-01.04.2018, University Cyril and Methodius, Technical Campus. 